\title{
Aproximaciones a Gabriel García Márouez. UNA PRESENTACIÓN
}

\author{
Noé Jitrik \\ Universidad de Buenos Aires
}

\section{Resumen}

Gabriel García Márquez es uno de los autores más influyentes de América y su obra ha sido pieza fundamental en la concepción del término "latinoamericanidad". Junto a Borges y Carrasquilla, entre otros, han desplegado visos esclarecedores no sólo para definir este movimiento, incluso lo caracterizan y estructuran. García Márquez incorporó propósitos de escritura que la cultura occidental no esperaba encontrar en la literatura del nuevo continente: Innovación en estructuras narrativas, consideración de la escritura como acto de reflexión constante y abandono de retóricas acartonadas; hechos que concedieron fuerza y libertad al espíritu descriptivo del escritor latinoamericano para nutrir un punto de vista literario de frente con la sociedad y el mundo que los circunda.

Palabras clave: García Márquez, latinoamericanidad, actitud designativa, palabra perifrástica, estructuras narrativas, superparodia.

\section{Approaches to Gabriel García Márquez: an introduction}

\begin{abstract}
Gabriel García Márquez is one of the most influential authors of America and his work has been a fundamental piece in the conception of the term «latinoamericanidad» (being Latin American). Along with Borges and Carrasquilla, among others, he has flashed the light not only to define this movement, but to characterize and structure it. García Márquez joined writing purposes that Western culture did not expect to find in the literature of the new continent: innovative narrative structures, consideration of writing as an act of constant reflection and abandonment of stilted rhetorical; facts that granted freedom and power to the descriptive spirit of the Latin American writer to nurture a literary point of view facing society and the world around him.
\end{abstract}

\footnotetext{
${ }^{1}$ Ensayista, novelista, poeta, periodista, compilador e historiador argentino; autor de diversos libros sobre la literatura latinoamericana. Desde 1997 es director del Instituto de Literatura Hispanoamericana de la Universidad de Buenos Aires.
} 


\section{Noé Jitrik}

Keywords: García Márquez, latinoamericanidad, designative attitude, periphrastic word, narrative structures, superparodia

\section{Polos y acercamientos a la situación de la obra de García Már- quez}

Hay que empezar por señalar, en cualquier acercamiento a la obra de García Márquez, que se ha constituido en una especie de fenómeno cuya forma es el aluvión; caso único, tiene su antecedente, quizás, en Neruda, aunque le lleva ventaja en cuanto a la atención que se le presta. Por ello, no resulta fácil presentarlo pues en realidad está hiperpresentado: quien se ocupe hoy de literatura latinoamericana posee un conocimiento de su obra, se ha hecho cargo de resonancias que le son propias. No queda, entonces, otro camino que hacer una navegación entre escollos, que lo son precisamente porque son conocidos, procurando formular algunas hipótesis que permitan ordenar el campo de otro modo.

El primer punto tiene que ver con la "situación" de García Márquez: es uno de los polos posibles de la literatura latinoamericana, un "modelo", definido como tal desde un sistema de difusión que posee un extraordinario poder. De este modo, escribir como él es una forma de ser $\mathrm{y}$, al mismo tiempo, una especie de prueba concreta de un programa posible; se trata de una mirada exterior que opaca, por el momento, otras tentativas y ello tiene que ver con valoraciones o sistemas de valores. El millón de ejemplares de Crónica de una muerte anunciada, por ejemplo, silencia, sin duda, los dos o tres mil ejemplares de textos que tienen lo suyo, aunque lo suyo no sea Crónica de una muerte anunciada. En suma, existen otras encarnaciones del imaginario latinoamericano pero también hay que decir que están, relativa y provisoriamente, oscurecidas de entrada.

Sin embargo, la idea de "polo posible" es abierta y promete un acercamiento porque lleva a considerar algún otro polo que, para la ocasión, podría ser Borges. Si los aceptamos como compartiendo o repartiéndose un espacio podemos iniciar algunas conjeturas.

Dicho de otro modo, a partir de este punto se formula un programa de reflexión que tiene por lo menos tres puntos: 


\section{¿En qué consiste y cómo opera esa mirada exterior que convier- te a García Márquez y a Borges en "polos"?}

Es probable que otros grandes escritores latinoamericanos no hayan desempeñado un papel semejante, al menos en las proporciones que observamos en estos dos; la obra de Carpentier, por ejemplo, se filtra con mayor lentitud y la de los escritores de comienzos del siglo XX no ha trascendido, por lo general, las fronteras nacionales, salvo acaso la de Darío y Martí pero su gravitación se ha producido en un ámbito más restringido; los escritores de vanguardia, a su vez, quedaron por lo general enquistados en sus propias experiencias.

Pero, ¿qué quiere decir ser un escritor "mirado"? Muchas cosas: leído (bien o mal), recorrido, citado, presente, invocado, considerado. En suma, es la mirada que la sociedad dirige en determinado momento sobre la obra de un escritor, la sociedad como un laboratorio que, además, la procesa y emite juicios. Esa mirada, a su vez, es diversa:

a. "Ser visto". Para el caso, ¿cómo son vistos García Márquez y Borges? Para responder hay que considerar, ante todo, la "amplitud real de lectura" que los tiene por objeto y que queda probada por un sistema de citas. Luego, hay que tener en cuenta la "repercusión social" de quienes han producido una obra así citada. Este aspecto interesa menos, pero la "repercusión" puede traducirse por valores tales como el éxito, la promoción, los premios, la provocación a la crítica, el consumo social de literatura, el sistema económico instaurado, etc.

b. "Travesía". Los textos de uno y otro implican y desencadenan viajes; hacia afuera, en la lectura que suscitan, desde la glosa más inmediata al psicoanálisis más refinado y, hacia adentro, al considerarse la obra de Borges como metáfora transdiscursiva y la de García Márquez como saga, como alteración de una retórica narrativa y como recuperación y transformación de tradiciones.

Dejemos a Borges en su esfera y sigamos a García Márquez en este punto: por saga se puede entender un encadenamiento de texto a texto, a partir del campo referencial que tiene cierto carácter obsesivo: temas que reaparecen y que ligan todas las obras -la soledad, el sueño, la muerte, el desafuero, la decadencia, la longevidad, el tiempo circular, la memoria-, o bien personajes que reaparecen o perduran de texto en tex- 
to. También hace a la saga que en la retórica narrativa el cuento deviene crónica y la crónica novela corta y, por fin, novela histórica y parodia. Y, por fin, determinadas "tradiciones", en particular la del relato de la selva -lo que va de José Eustasio Rivera hasta Horacio Quiroga-, así como la de "lo real maravilloso" (Asturias y Carpentier), el realismo mágico (Jorge Zalamea), y el modernismo, como una inflexión que se asume -en los restos gestuales y escriturarios- al tiempo que se combaten mitos colombianos del modernismo (Guillermo Valencia), que son objeto de ataque y destrucción.

c. "Concentración". Hay en ambos un efecto de economización verbal que tiende a depurar y a esencializar, de carácter inverso al de la simple experimentación: ambos tienden a la síntesis, lo que llamaremos "concentración".

\section{¿Qué quiere decir "polo" en esta perspectiva?}

Este término no es una categoría literaria; a lo sumo describe, pagando tributo a la imprecisión. No obstante, permite un acercamiento a la "situación" de una obra, indica dónde está puesta en relación con otras. Tal vez su concepto podría ser equivalente a "modelo homogéneo construido", o sea algo que sirve, desde la crítica, para conferir identidad a una obra, para traducir una intuición a una explicación. La intuición es un mecanismo operativo basado en un saber y en una experiencia, pero es inicial y, por lo tanto, necesita de una articulación posterior; desde la crítica, esa articulación da forma a la identidad de un texto lo que permite, también, entender un campo más amplio del cual ese texto forma parte. Por ello, decir "polo" es lo mismo que decir "modelo construido", pero construido por nosotros. Así entendido, el polo es describible; una de sus cualidades es ser "imitable"; otra es ser "correctivo" -esto es en Borges un lugar común; después de él, se dice, ya no se puede volver atrás-; por fin, es productor porque de esos modelos pueden salir nuevas formas.

\section{¿Qué desprendimientos se producen a partir de estos polos?}

Para responder a esta pregunta dejo de lado lo que puede ocurrir con Borges así como la "influencia” directa que ejerce García Márquez 
en escritores como Isabel Allende, que reproduce cualidades y tópicos de su esquema narrativo a punto tal que parece parodiarlo. Más bien, quiero referirme, en primer lugar, a aspectos productivos: Cien años de soledad puede ser visto como culminación de una línea precedente, a la que, simplificando, podemos designar como "realismo mágico" aunque en esta obra no se manifiesta como "tendencia literaria" sino como un modo de imaginar que da lugar a una escritura de atmósfera. García Márquez imagina poéticamente, lo que hace que proponga algo nuevo, sin mucha relación con el surrealismo que pudo haber alimentado a los predecesores, Asturias o Carpentier o Zalamea.

En segundo lugar, es notable una "actitud designativa", que aparece como una poética vinculada, tal vez, con el postulado saussureano de la arbitrariedad de la relación entre signo y cosa, en una atmósfera cercana a la que crea Foucault (Las palabras y las cosas). Si la "actitud designativa" existe manifestaría una preocupación teórica, aparentemente desligada de cualquier preocupación narrativa. Y por "designación" debe entenderse que la palabra lo inaugura todo; su contraparte sería la "peste del olvido", que no haría otra cosa que poner en evidencia que, si bien la palabra designa el olvido, amenaza la relación que la palabra establece con el mundo.

En tercer lugar, la cualidad polar tiene también el alcance de un "redimensionamiento epistemológico", en el sentido de inaugurar, en la estructura narrativa misma, una perspectiva psicoanalítica, que se manifiesta tanto en Cien años de soledad (el incesto), como en El coronel no tiene quien le escriba (estructura de denegación). Complementariamente, se produce un cambio en el sentido de que una novela en principio "de familia" -en la tradición burguesa- pasa a ser "novela de estructura", en el sentido lévistraussiano de las "relaciones de parentesco" a partir del juego entre prohibición y ley.

Este rasgo -la designación- se vincula con una problemática lingüística y filosófica pero también con modelos literarios que alimentan su escritura; es el deslumbramiento por Conrad, Hemigway, Faulkner y, en general, por escritores que apuestan narrativamente a la designación. Estos rasgos serían los que permiten suponer los "desprendimientos" a los que me referí; algo así como una "genética invertida": si la designa- 
ción es condición para la descripción, una sobrecarga opera una suerte de cambio cualitativo y dialéctico; genera otra cosa que puede llamarse "barroco" que aparecería, entonces, no como saliendo de la obra de García Márquez sino en una articulación de la cual la obra de García Márquez podría ser un "centro hipotético". En otras palabras, esa cualidad designatoria reaparece potenciada en otros textos que se reúnen en una categoría estilística más general que se reconoce como "barroco"; si esto es así, vista como "polo", la obra de García Márquez dejaría ver una distribución de líneas en el resto de la narrativa latinoamericana.

\section{La obra de García Márquez en particular}

\section{Colombia-Latinoamérica}

Pareciera que los textos de García Márquez van y vienen entre lo colombiano en particular y lo latinoamericano en general, términos que no son antagónicos pero cuyas relaciones de implicación son perturbadoras. Parece una obra muy colombiana pero al mismo tiempo es vista y sentida muy espontáneamente como latinoamericana. Esto se entiende por contraste: hay otras obras que pueden ser igualmente locales pero que no son vistas más que como eso; la obra de García Márquez parece viajar cómodamente por todo el continente.

Ahora bien, es obvio que es colombiano porque nació en ese país y se formó en él pero también porque su propuesta narrativa no sólo se recorta sobre la tradición literaria de su país sino porque modifica, ante todo, la escritura de su país: reanima una prosa lánguida y pretendidamente perfecta, que proclamaba para sí, como la cultura toda, el dudoso blasón de emplear el mejor español del continente; García Márquez derriba ese panteón.

Sólo sus primeros trabajos (La hojarasca, Los funerales de Mamá Grande y Ojos de perro azul) fueron escritos en su país; el resto lo fue en otros lugares y su regreso triunfal a Colombia se produce vía Buenos Aires y México, país donde escribe casi todo lo demás. Como se sabe, la repercusión que tiene Cien años de soledad es el punto de partida de una irradiación que no cesa y que fue designada con el nombre de boom. Pero, por otra parte, es el escritor que más se beneficia de un supuesto 
de latinoamericanidad quizás porque es quien más vive ese carácter tal vez por razones físicas (varios países de residencia), tal vez porque en su obra se reconocen elementos que serían componentes básicos de un lenguaje común a todas las culturas del continente. Pero también es evidente que no ha renunciado a la memoria anecdótica - sigue escribiendo sobre el mundo en el que se formó - ni al color local en la representación de lugares y situaciones ni a la tradición narrativa, hasta cierto punto canónica: Isaacs, Rivera, Carrasquilla. El punto en el que esa tradición opera, con las modificaciones que produce el "piedracielismo", es la poesía, que según sus declaraciones constituye su discurso fundamental: no sólo se formó en la poesía, no sólo se pensó como poeta sino que la poesía constituye su horizonte escriturario superior.

Es compleja la relación con la poesía y algunos de sus protagonistas. Por ejemplo, Álvaro Mutis: algo mayor que él, según declara el propio García Márquez, en él se origina el tema que dará lugar a El general en su laberinto. Uno y otro, así como el grupo de amigos (Álvaro Cepeda, Alfonso Fuenmayor, Germán Vargas), que aparecen como personajes transformados tanto en El coronel no tiene quien le escriba como en Cien años de soledad, han sido tal vez herederos igualmente del intento vanguardista de Jorge Zalamea y vinculados con el ámbito elaborado por Eduardo Zalamea, la zona guajira costeña, predilecta también de García Márquez.

Rafael Humberto Moreno Durán, en De la barbarie a la imaginación, señala que pese a la relación con "Piedra y cielo" y los mencionados escritores, el ambiente cultural en el que se movió era tan precario que los elementos que le brindó no explican esa obra ni fueron suficientes para elaborarla, en la medida en que en ella coexisten "pretensiones ecuménicas y méritos estéticos". En este caso, la pobreza llevó a los escritores a un plan sistemático de saqueo cultural. Al recordar su paso por Barranquilla y la enfermedad que lo postró durante tres meses, García Márquez evoca la librería de Ramón Vinyes (el "librero" de Cien años de soledad) y cómo sus amigos le enviaron un cajón de libros que devoró: Faulkner, Virginia Woolf, Sherwood Anderson, John Dos Passos. Estas lecturas, declara, le cambiaron la perspectiva: el método narrativo de La hojarasca es totalmente woolfiano. 
La idea de que el ambiente cultural no proporcionó elementos para tramar una obra, según Moreno Durán, favorece otra, la del "prodigio" o la excepción. Quizás se pueda ver la cuestión desde una perspectiva diferente; según esa idea, la "pobreza" se referiría al campo de los referentes, visto desde una exigencia tradicional europea, y la "riqueza" a ciertas capacidades de transformación en la escritura. A la vez, la reflexión se hace cargo de una axiología latente y culturalizada, que se traduce por una claridad en relación con lo "que debe" ser representado y de lo cual es ejemplo nítido el arte neoclásico.

A estas direcciones hay que añadir la experiencia política, que también lo formó. Por cierto, comparte con otros escritores esas experiencias. Experiencia fundamental fue en 1948, cuando se produce el "bogotazo", que despierta a la dimensión latinoamericana a muchos escritores colombianos. Una suerte de despertar que lo hace literariamente volver atrás y satura el presente: la historia está ahí. No cabe duda de que la fundamental experiencia del "bogotazo", como momento de crisis de un sistema político y cuya consecuencia es renovar la guerra civil que azota a Colombia desde tiempos remotos, debe haber implicado un cambio fundamental en el modo de ver la tradición y las posibilidades de realimentarla. El "saqueo" del que habla Moreno Durán aparece metafóricamente como una transposición y una salida; se trata de dejar atrás una retórica acartonada así como un sistema político que sólo renueva las formas de la guerra. Así, es el propio García Márquez quien establece las relaciones: "En ese momento (dice en la aludida entrevista), la aplicación que había por la poesía era la misma que hay con el M19".

En cuanto a Latinoamérica, García Márquez parece funcionar en un acorde muy cercano a esa imagen del "saqueo" que parece esencial a la noción de latinoamericanidad; más particularmente, se identifica por una "dicción", en el sentido de un trabajo que se realiza sobre una lengua general que no es antagónica de particularismos: sin renunciar a lo local se centra en un "decir" narrativo como programa de escritura con ingredientes modernistas. Y, quizás, eso explica la sobrecarga verbal de El otoño del patriarca, novela en la que por añadidura Rubén Darío se desempeña como personaje. 
¿Qué toma del modernismo? Sobre todo la teoría de la imagen; además, el espíritu descriptivo: sus descripciones nunca son de tipo realista referencial, no trata de configurar un cuadro apostando a la verosimilitud; al contrario, su descripción es alterada en virtud del bombardeo constante de imágenes y de una adjetivación no calificatoria sino ampliatoria; lo que produce se inscribe en una práctica verbal que podríamos designar como "latinoamericana". Es claro que no se trata de que el lenguaje latinoamericano se caracterice exclusivamente por un modo de adjetivar tendiente a la imagen sino tan sólo de que esta tentativa busca generalizarse.

Se diría, en este sentido, que los peculiarismos no serían garantía de autenticidad; sí lo serían, en cambio, conflictos situados en el orden de la lengua así como en el orden de la conciencia y, sobre todo, en el de la carencia. A partir de la percepción de esos conflictos, lo local - sin ser abandonado como punto de partida referencial - puede irradiar sobre un orden mayor y devenir lo propio de él. Es, quizás, la famosa frase de Tolstoi "describe tu aldea y describirás el mundo", a la cual habría que añadirle: "pero no describas tu aldea sin tener en cuenta los conflictos de lengua que pueden ser de todo el mundo."

\section{La crítica}

Hay que señalar, para comenzar, que García Márquez ha sido leído abundantemente, en el sentido de una lectura de la crítica, tanto que sería imposible hacer una clasificación exhaustiva. Podemos, sin embargo, esquematizar los enfoques. Sólo a los efectos de ejemplificar señalaré los siguientes trabajos:

- En cuanto a un enfoque psicoanalítico clásico, Josefina Ludmer, Cien años de soledad: una interpretación.

- En cuanto a un enfoque sociocrítico, Javier García Méndez, El ser social del texto latinoamericano.

- En cuanto a un enfoque de tipo estructuralista, Tzvetan Todorov, Macondo en Paris.

- En cuanto a una búsqueda de símbolos y significados simbólicos, Graciela Maturo, Clave simbólica de Gabriel García Márquez.

- En lo que concierne a lo biográfico como clave para explicar una 
obra, Mario Vargas Llosa, Gabriel García Márquez: historia de un deicidio.

- Como lectura de desciframiento, Víctor Farías, Los manuscritos de Melquíades.

- Como clave latinoamericana, diversos trabajos de Ángel Rama.

En cada uno de estos rubros podrían incluirse otros títulos más, sin contar las entrevistas que le han hecho y en las cuales hay material para construir su pensamiento sobre muchos aspectos de su obra. Una parte apreciable de esos trabajos persigue claves significativas, como si esa obra incitara a desciframientos, a la determinación de un "querer decir" fascinante. Los seguidores de Maturo miran los textos como metáforas de situaciones más amplias, por ejemplo "América Latina como mujer dominada". Pero, si siguiéramos la crítica en su historia podríamos advertir cómo van variando los modelos explicativos, desde el estructuralismo hasta la carnavalización bajtiniana, pasando por los esquemas culturalistas de Benjamin y el psicoanálisis freudiano y lacaniano. Diversos modelos críticos pueden haber hallado en la obra de García Márquez razones válidas para ser aplicados, todos pueden haber encontrado algunas parcelas de verdad o de esclarecimiento pero, en todo caso, esa obra parece reclamarlos y promoverlos.

Todos los estudios que se han hecho hacen difícil una investigación de alcance global; casi todo ha sido dado a conocer, aunque lo que sí puede hacerse es recuperar imágenes parciales $\mathrm{y}$, tal vez, producir otros modelos de análisis posibles. En ese sentido hubo una innovación importante al considerar Crónica de una muerte anunciada como parodia; hasta ahora sólo se había recordado esa noción parcialmente, como calificación al considerar Cien años de soledad como parodia de la cultura occidental.

En cuanto a mi propia lectura, hay una historia que comienza con un trabajo sobre Cien años de soledad, sigue con otro sobre El coronel no tiene quien le escriba y finaliza con algunas reflexiones sobre los últimos textos. La lectura de Cien años de soledad tenía una fuerte impregnación estructuralista y dio como resultado un trabajo que se tituló "La perifrástica productiva en Cien años de soledad". La palabra 'perifrástica' tenía un sentido ordenador, no era un refugio gramaticalista; se 
trataba de entender toda la novela como una relación entre tres tiempos: un pasado de la narración, un futuro de la predicción y un presente del narrador. Esa relación organizaba todo, al menos era la hipótesis que traté de demostrar. El análisis que hice descansaba en un esquema de recepción: siempre hay un destinador, siempre hay un destinatario, algo que viene y algo que está. Pero la recepción a la que me refiero supone un encuentro entre lo que llega y las situaciones que genera la escritura. Y hay también un lugar central de encuentro; en este texto es la "casa", palabra que, por otra parte, era el título inicial de este texto.

La "casa" no es sólo el lugar común, lo obvio residencial sino también una estructura, algo instalado en el inconsciente, algo que se busca y se pierde, permanentemente en riesgo. Entre lo que está, la casa, y lo que llega a ella, surgen cambios, avatares; a su vez, el núcleo de la casa es el "cuarto de Melquíades", o sea el lugar de la escritura. En suma, todo el relato tendría un fundamento o un objeto secreto, que es lo que lo produce.

El trabajo sobre El coronel no tiene quien le escriba elabora tres "frases productivas": "Después de afeitarse al tacto, pues carecía de espejo desde hacía mucho tiempo, el coronel se vistió en silencio"; "Yo no tengo quien me escriba"; "No se sabe -dijo-. Es difícil leer entre líneas lo que permite publicar la censura." De lo que resulta del examen de cada una se compone un modelo del texto, pero la frase especialmente central es la segunda que reaparece invertida en boca de otros ("El coronel no tiene quien le escriba"). Pues bien, esa declaración no impide al coronel ir a buscar la carta de todos modos; ello permite establecer una estructura de denegación sobre la cual escribió Freud y retomó Octave Mannoni. Dicha estructura pone en movimiento coadyuvantes narrativos (personajes casuales, réplicas, comportamientos, historias) y por ello la considero "productiva". Se trata de lo que Freud llama una "creencia" y que es no sólo acción del inconsciente sino la condición misma para el reconocimiento de la diferencia, incluso la sexual. En el caso de García Márquez es la base del relato de lo que no puede ser porque ya se ha dado y no puede modificarse, en suma, la situación trágica por excelencia. Ahora bien, si esto es así en el relato de 1959 y esto es la base de la tragedia, Crónica de una muerte anunciada no sería más que la escritura de la tragedia ya consumada. 
Del examen de la tercera frase surge una teoría de la escritura y de la lectura. ¿Cómo y qué se lee? Si la escritura se produce para ser leída, la interferencia del poder obliga a leer entre líneas; esta lectura es la verdadera. A su vez, esa escritura censurada -los periódicos- trae en su interior folletos clandestinos, no censurados, pero que nadie lee. La lectura, en consecuencia, es entendida como bloqueo, como límite que hay que trascender para encontrarse con la escritura.

\section{Parodia, tragedia, hechos}

En cuanto a Crónica de una muerte anunciada, se presenta como tragedia pero lo que importa no es llegar a una conclusión acerca de un suceso, que es lo propio de la tragedia, sino su reconstrucción; como se advierte, el anuncio no sólo es reiterado sino que el hecho se ha cumplido cuando regresa el anuncio y, sin embargo, un relato se constituye; esto quiere decir que lo que importa es la escritura y no el destino trágico del personaje, cosa que, en cambio, es lo que más importa en una tragedia clásica. Se podría decir que Crónica de una muerte anunciada constituye una variante frente a la novela burguesa tradicional; si en ella lo fundamental (Luckacs) es la búsqueda de valores puros que hace un héroe degradado en un mundo igualmente degradado -con resultados en dos vertientes, la redención del mundo o la ratificación de su degradación- el héroe fatalmente es caracterizado como perdurable, pulsionalmente invencible. Freud completa la percepción de Luckacs y la relación entre ambas líneas explica la idea de riesgo, desafío, combate, triunfo, derrota parcial. En la novela burguesa el héroe perdura hasta el final y su muerte es el fin del relato. En este texto no es así, la invulnerabilidad del héroe está descartada de entrada, el "yo" es liquidado antes de comenzar y su lucha es inútil.

Hay, entonces, un desplazamiento hacia la narración misma que presenta la posibilidad de reconvertir el gesto literario, como sería la tragedia o la crónica, y establecer un continuo paródico entre ambos, como culminación, en gran medida, de un proyecto cuyos inicios, y en forma constante, estaban impregnados de una preocupación básica en torno a problemas de escritura y lectura. 


\section{Algunas reflexiones sobre Crónica de una muerte anunciada}

La idea de crónica, obviamente, tiene una base temporal. Implica el seguimiento de un hecho en su desarrollo para transmitirlo como suceso con la finalidad de que ese suceder dará lugar a alguna significación. En el orden periodístico esto es claro: se hace una crónica de algo que se supone importante y al hacerla se crean las condiciones para que tal relevancia se manifieste. Por ello, las crónicas se abren con gran expectativa y suelen terminar en frustración si no hay un hecho interesante que la justifique. Por el contrario, si ocurre algo, un rasgo de ingenio o un atentado o lo que sea, la crónica se justifica plenamente.

Esta aproximación emparenta la crónica con el discurso histórico. La crónica tiene más que ver con la información mientras que lo que justifica el discurso histórico es una voluntad de iluminación. Periodista e historiador siguen un hecho pero mientras uno trata de perfilarlo el otro intenta connotar lo fáctico mediante interpretaciones que tienden a determinar la lectura de ese hecho. En el periodismo el seguimiento postula tal proximidad que pareciera renunciar a toda ilusión interpretativa, cosa por lo demás imposible puesto que el lenguaje, como interpretante en sí mismo, lo impide.

García Márquez no sólo es autor de este libro sino también, con más inscripción periodística, de La aventura de Miguel Littín clandestino en Chile y, por el otro lado, con inscripción histórica, de El general en su laberinto. En todos los casos se trata de seguir un suceso: en la Crónica como en El general ese suceso es una muerte. La de Bolívar no es anunciada, como la de Santiago Nassar, sino prevista en dos instancias: la del relato y la de la historia; el cruce de ambas da lugar a la llamada "novela histórica". Y, vista la proximidad de ambas líneas, se podría pensar en la perduración de una estructura en el espíritu del escritor, una constante o un elemento que no se agota, perduración o insistencia, que da lugar a un ciclo. En ese caso el elemento, obsesivo, enigmático, es la muerte de un hombre. Por lo tanto hay en ambos casos reconstrucción de algo ya sabido, aunque por diversos medios. Que se haya dicho que Nassar sería asesinado y que lo fuera luego es lo sabido; por otro lado, la historia nos ha hecho saber cómo Bolívar murió. En la Crónica esa reconstrucción se hace a través de un método indagatorio, vinculado a 
una estructura de tipo policíaco; en El general la reconstrucción tiene una base documental cuyos núcleos son ficcionalizados por subjetivación, expresión, ambientación, introspección.

Además, la comparación tiene interés para mostrar de qué modo la "saga", que supone continuidad de propósitos en el orden semántico, ha alcanzado en estos textos un nivel discursivo, es decir que opera no ya meramente en el orden de los actantes ni de los lugares ni de las situaciones recurrentes sino en el de la construcción; lo que ahora se continúa ya no son temas sino estructuras que sirven a diferentes articulaciones y que permiten la narración. ¿Cuáles son esas articulaciones? En un caso la parodia, en el otro la novela histórica aunque, por las características de su actuación narrativa, ni la parodia aparece como tal ni la novela histórica respeta sus objetivos clásicos.

En cuanto a la parodia se diría que hay un doble disfraz: el gesto paródico es el primero respecto de lo parodiado pero al ser ocultada esta operación tras la crónica, toma forma un segundo nivel de disfraz. La novela histórica, a su vez, no pretende mostrar un aspecto oscuro de la historia para reinterpretar el presente, como era, según opinión generalizada, el objetivo que perseguía este género; Bolívar es alguien muy estudiado y los días de su muerte son los mismos que narra García Márquez.

Se diría que no hay en verdad seguimiento de ningún suceso sino reconstrucción a partir de fragmentos de testimonios de diversa fuente: recuerdos del narrador y de otros, conjeturas, rectificaciones de unos y otras, cada fragmento es sometido a una prueba de validez por parte del narrador. Entre el hecho y la articulación reconstructiva hay una suerte de distancia a la que podemos darle el nombre de "espacio literario", que sería un vacío entre dos líneas que parecen ser muy concretas porque responden a retóricas muy codificadas que en sí mismas podrían no ser literarias; de este modo, trazar un seguimiento puede ser la condición necesaria pero no suficiente para hacer literatura y, correlativamente, reconstruir puede no ser necesario pero, en el caso, resulta suficiente. En otras palabras, ése es el espacio de la escritura entendida como sistema de operaciones que dan lugar a textos. 


\section{Transformaciones: textualidades}

Ahora bien, ¿cuáles son las transformaciones que tienen lugar en el espacio de este texto en particular? Por empezar, mencionemos el referente, una muerte recordada y, por lo tanto, anterior al texto, extratextual. García Márquez lo indica: hubo un asesinato en su pueblo, que le interesó, pero su madre le hizo jurar que no haría nada con eso hasta que todos los protagonistas hubieran muerto; treinta años después, considera cumplida su promesa y se siente autorizado a ocuparse de ese recuerdo. Tenemos, entonces, una "ilusión referencial", como diría Greimas, que el propio autor ha configurado, pero que cambia de índole en una sucesión vertiginosa, que sólo se puede describir por análisis. Por ejemplo, la "prohibición" que el hecho ha generado sería la operación transformativa primera de modo tal que el asesinato cambia de forma. Sin embargo, la memoria no cede y en esa persistencia hay otra operación: el hecho adquiere espesor; luego, cuando viene la "autorización", hay otra operación, liberadora en este caso, que se convierte en una "búsqueda" reconstructiva de todas las etapas, para dar lugar, finalmente, a la "organización" del relato, en suma a la instancia narrativa. La suma o el conjunto de estas operaciones indica o sugiere lo que puede ser la "escritura": las operaciones interactúan y van modificando una forma que entrega algo a la forma final del relato.

Se trata, entonces, de un desplazamiento, en virtud del cual el hecho desencadenante pasa a un segundo plano alterando, incluso, la idea de tragedia implicada en el "anuncio" porque predomina la articulación sobre el efecto moral y aun sobre el desarrollo de un saber de lo fáctico: todos se declaran incompetentes para hacer una interpretación, seguimos como antes, en la ignorancia del ofensor y sin saber por qué no se aclararon las cosas a tiempo. Y si la búsqueda implicaba una "promesa", lo que permitía pensar en una estructura más o menos policíaca, el seguir con el enigma intacto lleva a una frustración y a un recorte de los alcances del género.

Estas observaciones indicarían que algunos sectores del texto establecen contacto con órdenes literarios diferentes que si, por un lado, contribuyen a dar consistencia al relato suponen, por el otro, una mirada que se gratifica observando de qué modo el texto escapa a esas tenta- 
ciones. Dicho de otro modo, en un texto puede operar una "red de pescador" en la cual cae algún pez genérico que ha creado una expectativa subterránea; pero esos peces, y ahí la red devela, no llegan a comerse la narración. En cuanto a lo policial, por ejemplo, hay promesa y correlativa frustración: el relato es algo más.

Si lo esencial, como insisto, es la articulación, ciertas alternativas -soluciones a enigmas- ya no son posibles; sabiamente, el narrador las deja de lado, con toda claridad. Ello no ocurre, me parece, en El general en su laberinto. En cambio en Crónica lo único que se refiere es los "modos de referir" de donde, si eso es equivalente a escribir, este texto es sobre escribir. Esto abre, muy naturalmente, un espacio para la parodia, concepto que implica confluencia de nociones o, lo que es lo mismo, procedimientos operacionales.

Una de estas "nociones" es lo que podríamos designar como "intratextualización". Para explicar este concepto hay que decir primero que si Crónica forma parte de un corpus mayor, un texto entre otros de un autor, traer algo de esos otros a éste es "intratextualizar"; por lo tanto, el elemento traído puede ser considerado "intratextual" y es sometido al orden que predomina en el nuevo texto: se lo "contextualiza". Lo que llamamos "escritura parcial" sería, entonces, la reunión de lo "intratextual", como campo de selección, y de lo "contextual", como momento de producción. Así, se hace aparecer al Coronel Aureliano Buendía de un modo semejante al que se empleó para hacerlo aparecer en El coronel no tiene quien le escriba; en este caso, un personaje, un coronel que actuó en las guerras en las que Aureliano era jefe, asistió a la rendición firmada por aquél; en Crónica, Aureliano Buendía es mencionado como derrotado por el general San Román, personaje episódico aunque significante, en Cien años de soledad apenas mencionado.

Este mecanismo es leve, es un toque o una tenue presencia que no altera otra noción más densa, lo "autobiográfico", es decir el sistema de operaciones narrativas ligadas por la primera persona. En este texto está encarnado en un ser histórico, un narrador con nombre y apellido, su madre y sus hermanos como coadyuvantes. En virtud de ello, tiene un tono de cercanía y sinceridad, el narrador se presenta como un ser próximo a los hechos y desinteresado en cuanto a un protagonismo, 
sólo aspira a ser un "esclarecedor", todo lo cual sería garantía de verosimilitud. En otras palabras, el mecanismo de lo autobiográfico constituye la principal fuente del engaño, de modo equivalente a lo que es en principio la verosimilitud. Por lo tanto, la cercanía, cuya virtud o pretensión es crear una zona incuestionable, es objeto de parodia en la medida en que ese "yo sé porque estuve" pretendería discursivamente afirmar pero no asevera nada.

Se podría decir, a este propósito, que este modo de establecer relaciones instaura un ámbito discursivo o, al menos, una posibilidad de considerar los efectos que produce el juego interno de un texto. Y, para sostener aún más este enfoque, se diría que actúa algo más, una noción de "testigo", diversa de lo "autobiográfico" y que remitiría a lo jurídico.

Estas, y otras nociones, interactúan y neutralizan lo que implicaría el predominio absoluto de una de ellas; y como ninguna predomina, este relato no es ni invención total ni rememoración fiel. Si predominara lo autobiográfico sería una cosa; si, en cambio, predominara la noción de "intratextualidad", podría llegar a ser "superparodia". Como nada de ello ocurre, este texto es un híbrido, ni totalmente referencial ni fantástico, ni testimonial ni paródico. Y, para mostrar la alternancia de nociones, se puede invocar el manejo de los nombres; están los verdaderos (el de la madre, la hermana, la novia) junto a otros que proceden de la literatura y a otros tan rebuscados que, aunque no sean falsos, en tanto salen del santoral, sugieren una fuga o un juego de fuga.

Sea como fuere, lo que importa es la "contextualización", o sea el encuentro o choque de operaciones. En otras palabras, introducir todo -real o ficticio, hallado o buscado, memoria, intra e intertextualidaden el espacio literario para armar un relato falso, o sea, no el relato de cómo y por qué se produjo una muerte sino el relato de su constitución como tal.

\section{Por último: la parodia otra vez. Y la intención}

Y si el relato es paródico lo parodiado sería recuperable por análisis aunque, desde luego, el texto paródico es mucho más rico que el punto de partida. Por eso, puede ayudar otro elemento propio de la parodia, la “intención”. ¿Cuál sería en este caso? Habría que hablar como objeto de 
esa intención de un conjunto de prácticas que implican por un lado un orden de afirmación y de promesa y, por el otro, muestran lo que efectivamente dan y no dan. Como promesa es un modo de la ilusión, una interpretación codificada del deseo de ponerse a disposición de reglas preexistentes aunque es muy probable que nadie crea que el deseo se satisfaga. En otras palabras, lo más probable es que ninguna operación que se apoye en alguna de esas retóricas haya estado al margen de la frustración.

Volviendo al texto habría una intención de investigar al reconstruir el hecho, determinada y dirigida por un discurso jurídico ausente. En este caso, lo policial (investigación) se ve atravesado por lo que tiene de jurídico que no aparece.

La novela, toda novela es el desarrollo de un ya sabido pero por la vía del ocultamiento de ese saber más que de la develación; de esa idea surge la noción del "suspenso" que, como administración de ansiedad, puede formar parte, deliberadamente o no, de la intención.

Entonces, ¿cuál es la intención, y la intención paródica? Se diría que es dar vuelta la promesa genérica y poner en evidencia que lo que interviene en la conformación del texto paródico, en el cual resuenan los ecos en sordina de las reglas parodiadas.

Pero hay algo más, un procedimiento de "inversión" que tiene diversos registros, por ejemplo, en la categoría del héroe, tan importante en la tradición del relato. Santiago Nassar, cuya historia se narra en la Crónica, no es héroe como tampoco lo son los restantes personajes, considerando que en el paradigma occidental del relato el héroe es una instancia semántica, la culminación de la función concentradora que ejerce el personaje, $y$, como tal, encarna valores extratextuales que se defienden o que se combaten. En Crónica no hay héroe, la muerte de Santiago Nassar lo justifica como personaje pero no sus acciones; carece de peripecia, sus desplazamientos duran poco y el valor que tienen es ser objeto de interpretación posterior. En suma, hay una inversión suave que promueve un desplazamiento hacia una función central enunciativa, la articulación. 


\section{Final: perifrástica}

En las narraciones precedentes de García Márquez no se registra un desplazamiento semejante; en El coronel, por el contrario, se trata de un ir y venir que genera acciones ligadas, a su vez, en un sistema global de producción de significación. En La aventura de Miguel Littín clandestino en Chile hay crónica de un héroe, lo que hace que se reduzca el espacio literario y el texto se inscriba más en el discurso periodístico.

La Crónica, cuyo origen fue cuasi familiar, difiere en ese sentido, de El general en su laberinto que, a partir de una idea de Alvaro Mutis, llevó a documentarse. El proceso de escritura se inicia, por lo tanto, en ambos casos, sobre estructuras previas, pero diferentes; en cuanto a la Crónica es una ocurrencia; en El general, es una sugerencia y una investigación a lo cual hay que añadir la presencia de un juicio político, a saber la existencia de un generalizado sentimiento de riesgo que tiene que ver con el presente, es genérico y actúa en este caso como motivación, no plantea una relación de interpretación. Y, puesto que me refiero a El General en su laberinto, sugerencia, documentación, conciencia histórica, configuran el punto de partida de la novela histórica.

Pero hay algo común a ambos textos; si por un lado para desarrollar la narración sigue una estrategia que le debe casi todo a la crónica, por el otro se trata del registro de los últimos días de Bolívar. Y si la llamada "novela histórica" es una elaboración del documento para hacerlo desaparecer en la ficción, el hecho de que toda la carga verbal se deposite en un personaje, más que en situaciones "históricas", constituye un límite que se salva mediante un exceso de ficcionalización y una artificiosa sobrecarga psicológica e ideológica: la abundancia verbal asume relieves psicológicos, recupera memorias, atribuye sueños y reinterpreta dicciones que pudieron haber sido de Bolívar y el todo culmina en, como en Crónica, en una muerte. Viene, entonces, en ambos casos, en un "anuncio" que es un mitema de muchas formas en la cultura occidental, desde las luminosas anunciaciones del cristianismo hasta el mensaje ominoso o apocalíptico; la mántica sistematiza el mitema y refiere estructuras mentales muy arcaicas. A su vez, ese mitema tiene una particularidad: posee una estructura de tipo perifrástico, es decir que liga tiempos: el contenido de su afirmación remite al futuro (anun- 


\section{Noé Jitrik}

cio), el momento de su enunciación es de presente y el campo de sus supuestos se relaciona con un saber del pasado. "El día en que lo iban a matar" (pero no lo matan) se escribe en El general, frase que se vincula con el inicio de Cien años de soledad: "Muchos años después, frente al pelotón de fusilamiento, el Coronel Aureliano Buendía había de recordar...". Desde luego, el anuncio forma parte de la materia misma de Crónica y en El coronel no tiene quien le escriba es tan sólo esperado, el relato es de su ausencia. Por supuesto, el anuncio es de la muerte. Y, en ambos casos, triunfa sobre la perduración de un "yo", que sería el del personaje central. Figuración inhabitual pues el placer que provocan los relatos reside en la identificación que se produce en la lectura con el triunfo provisorio de un yo sobre la muerte. 